\title{
Analysis of the Motion of Some Brazilian Coastal Dunes
}

\section{Amelia Carolina Sparavigna ${ }^{1}$}

${ }^{1}$ Department of Applied Science and Technology, Politecnico di Torino, Torino, Italy

\begin{abstract}
Satellite images of coastal dunes of Brazil are showing an interesting feature. As we can see from images of Google Earth, these dunes are leaving, during their motion, some footprints behind, which are sedimentary patterns. Then, we can use the Google Earth images to follow year after year the motion of such dunes. Here we give some examples of the analysis we can perform on such satellite images, in particular for a remote monitoring of these moving dunes.
\end{abstract}

Keywords: GIMP, Image processing, Google Earth, Dune motion, Satellite images.

\section{Introduction}

Dunes are hills or ridges of sand that we can find in arid and coastal regions of the world. The dunes are created by the wind, which is moving and depositing sand; when winds are blowing in a prevailing direction, the dunes can move of several meters in a year, with a rate depending on their size and on local environmental conditions [1]. These complex systems made of sand, often assuming regular forms that can change with time, are the subject of several experimental and theoretical researches, which started with the pioneering works of Ralph Bagnold $[1,3]$. More recently, the studies have increasingly addressed the problem of dune stability in relation to climate changes [4-9].

It is very important to observe that coastal dunes, such as those of Brazil, can differ considerably from the desert dunes [10]. The internal structure is different because of a different cohesion within the sand. As observed in Ref.10, Brazilian coastal dunes are created under an environment rich of humidity and with heavy rainfall; in this manner, the avalanching of sand on the lee sides produces many distinctive features proper of wet cohesive sand. The roots of plants growing on the dunes contribute to form additional distinctive structures [10]. In any case, the coastal dunes can move. In the following discussion, we will see how to observe their motion from the time-series of satellite images provided by Google Earth.

\begin{abstract}
Before discussing their motion, let us note that the coastal dunes of Brazil are showing an interesting feature. They are leaving "footprints" behind, during their motion; these footprints are sedimentary pattern on the soil. As explained in [11], a reference which is discussing a large active dune-field of the eastern portion of Maranhão coast, the observed patterns are formed due to seasonal phenomena. During the wet season, interdune plains are flooded and the soil is reworked by intermittent drainages; during the dry season, the deposits formed by drainages and interdune lakes become temporary internal sedimentary sources for the system [11]. Here we give some examples of these patterns, besides showing how to measure the motion of dunes, which can be easily performed by a time-series of satellite images.
\end{abstract}

\begin{abstract}
Time-series
Time-series of satellite images, in particular those freely available from Google Earth, can help us in a remote monitoring of dunes. In some recent papers, we have shown a method to determine the drift of dunes using images of Google Earth [12-16]. In the given references, we have investigated in particular the motion of barchans. These dunes have a crescent shape which is aligned with the wind direction. Barchans are observed in areas where there is a hard ground surface, a moderate supply of sand and a constant wind direction. A surveying of dunes, which is often requiring large length- and timescales, can be easily made by means of the satellites
\end{abstract}

This article is published under the terms of the Creative Commons Attribution License 4.0 Author(s) retain the copyright of this article. Publication rights with Alkhaer Publications. Published at: http://www.ijsciences.com/pub/issue/2016-01/

DOI: 10.18483/ijSci.905; Online ISSN: 2305-3925; Print ISSN: 2410-4477 
working in the visible range and by those equipped to determine the local environmental conditions. Maps obtained from the data recorded by such satellites are available from NOAA federal agency [17]. Such remote surveying method can substitute the local monitoring, at least partially. Moreover, some of the satellite resources are freely available in the World Wide Web.

To obtain some data concerning the motion of dunes from the satellite images we can use the ruler tool of Google Earth of course, but also GIMP, the GNU Image Manipulation Program, as detailed in [14]. In that reference, we have discussed how GIMP tools can be applied to study the dunes. Here, we use the same method on the images of some coastal dunes of Brazil. Since these dunes are leaving "footprints" behind, which are noticeably evidencing their motion, we can easily follow their motion year after year.

In the Figure 1, we revise shortly how to apply the method [14]. Let us consider a solitary sand dune near Ilha Grande, a municipality located in the coastal region of Piauí (the solitary dune and the field of this region are shown in the Figure 1). Let us have two images from Google Earth time-series of this dune. One is dated November 2003, shown in Fig.1(a). The second is dated January 2016 in Fig.1(c). The image in the 1(b) panel is obtained from 1(a), by inverting colours. The images 1(b) and 1(c) are used as two semi-transparent layers to be merged with GIMP, to obtain the image in the right panel of Fig.1. The black and white areas show the different positions of the dune. Using the white area, and the ruler of Google Earth, we can evaluate that the dune moved of about $130 \mathrm{~m}$, during the considered time interval.

Before continuing our analysis of the coastal dunes, let us note that Brazilian dunes have been discussed in several references, for instance [18-25]. [18] and $[24,25]$ report of local investigations of the dunes of Jericoacoara.

\section{Motion and footprints}

Jericoacoara is a small fishing village, "mecca" of windsurfing and kitesurfing, in Ceará, Brazil. It is also the location of a large dune field. In Figure 2, we have two images from a time series of Google Earth showing some of the Jericoacoara dunes. As we did in the Ref.14, and shown here by Figure 1, we can measure the motion of the dunes of this field, comparing satellite images. Let us make this for the largest barchan of the dunes shown in Fig.2. The result is given in the Figure 3 .

As previously told, the Brazilian coastal dunes are leaving some traces on the soil, that we defined footprints, consequence of seasonal effects [11]. In Figure 4, two images of a time-series for another dune of Jericoacoara are given. Images are compared in Figure 5. In this case, we created this figure from two layers adjusted with GIMP Retinex filtering (for a discussion of GIMP Retinex, see please $[26,27]$ ). In the Figure 5, the red line marks the position of the toe of the dune in 2009, whereas the white lines mark its position in the previous years: these lines are evidencing the footprints of the dune.

The dune shown in Figures 4 and 5 had been investigated in [24]; besides a local analysis, a remote sensing evaluation was made using QuickBird satellite images ranging from September 2003 to September 2004, and extrapolations proposed about the dune behaviour on previous years.

Of course, footprints are not limited to the dunes of Jericoacoara. If we follow the Brazilian coast on Google Earth we can easily see them in the dune fields that we encounter. We have, for instance, those of Tutoia dunes, analysed in Ref.11. In the Figure 6, this location is shown, as in the following Figure 7 (in Figures 8-10, other examples are given of the possibility of following year after year the motion of the dunes). Moreover, let us also remember the Figure 1, which is concerning the dune field of the coastal region of Piauí.

Also for coastal dunes then, the satellite images of Google Earth are useful for having information on their behaviour. For instance, if the distance of the observed footprints changes, we can easily measure the variation of migration rates, which can be triggered by environmental factors. In any case, Google Earth is freely offering the possibility of a remote evaluation of the migration of dunes and an easy forecast of the problems for human activities that the dunes can produce. An example of a monitoring for this purpose is given in the Figure 11, concerning a location on the north-eastern coast of Ceará, where the dunes move of more than 10 meters per year.

\section{References}

1. Bagnold, R.A (1941). Physics of blown sand and desert dunes, Chapman and Hall, London. Printed by Springer in 1974. DOI: $10.1007 / 978-94-009-5682-7$

2. Bagnold, R.A. (1935). The movement of desert sand. The Geographical Journal, 85(4). Pages 342-365. DOI: $10.2307 / 1785593$

3. Pye, K., \& Tsoar, H. (2008), Aeolian sand and sand dunes, Springer. DOI: 10.1007/978-3-540-85910-9_10

4. Mischke, S., Zhongping Lai, Hao Long, \& Fang Tian (2015). Holocene climate and landscape change in the northeastern Tibetan Plateau foreland inferred from the Zhuyeze Lake record. The Holocene. November 3. DOI: 10.1177/0959683615612570

5. Thomas, D.S., Knight, M., \& Wiggs, G.F. (2005). Remobilization of southern African desert dune systems by twenty-first century global warming. Nature, 435(7046). Pages 1218-1221. DOI: $10.1038 /$ nature03717 
6. Hiza Redsteer, M., Bogle, R.C., \& Vogel, J.M. (2011). Monitoring and analysis of sand dune movement and growth on the Navajo Nation, Southwestern United States. U.S. Geological Survey, July, Fact Sheet 2011-3085.

7. Hereher, M.E. (2014). Assessment of sand drift potential along the Nile Valley and Delta using climatic and satellite data. Applied Geography, 55. Pages 39-47. DOI: 10.1016/j.apgeog.2014.09.004

8. Tsoar, H. (2005). Sand dunes mobility and stability in relation to climate. Physica A: Statistical Mechanics and its Applications, 357. Pages 50-56. DOI: 10.1016/j.physa.2005.05.067

9. Tsoar, H., Levin, N., Porat, N., Maia, L.P., Herrmann, H.J., Tatumi, S.H., \& Claudino-Sales, V. (2009). The effect of climate change on the mobility and stability of coastal sand dunes in Ceará State (NE Brazil). Quaternary Research, 71(2). Pages 217-226. DOI: 10.1016/j.yqres.2008.12.001

10. Mckee, E.D., \& Bigarella, J.J. (1972). Deformational structures in Brazilian coastal dunes. SEPM Journal of Sedimentary Research, 42(3). Pages 670-681. DOI: 10.1306/74d725f4-2b21-11d7-8648000102c1865d

11. Hilbert, N.N., Guedes, C.C.F., \& Giannini, P.C.F. (2015). Morphologic and sedimentologic patterns of active aeolian dune-fields on the east coast of Maranhão, northeast Brazil. Earth Surface Processes and Landforms, 41(1). Pages 97-97DOI: $10.1002 /$ esp. 3786 .

12. Sparavigna, A.C. (2013). A study of moving sand dunes by means of satellite images. International Journal of Sciences, 2(8). Pages 33-42. DOI: 10.18483/ijsci.229

13. Sparavigna, A.C. (2013). Moving dunes on the Google Earth, arXiv preprint arXiv:1301.1290

14. Sparavigna, A.C. (2013). The GNU Image Manipulation Program applied to study the sand dunes. International Journal of Sciences, 2(9). Pages 1-8. DOI: 10.18483/ijsci.289

15. Sparavigna, A.C. (2013). A case study of moving sand dunes: The barchans of the Kharga Oasis. International Journal of Sciences, 2(8). Pages 95-97. DOI: 10.18483/ijsci.241

16. Sparavigna, A. (2014). Peruvian transverse dunes in the Google Earth images. PHILICA.COM Article number 447.

17. NOAA National Oceanic and Atmospheric Administration, http://www.noaa.gov
18. Sauermann, G., Andrade Jr., J.S., Maia, L.P., Costa, U.M.S Araújo, A.D., \& Herrmann, H.J. (2003). Wind velocity and sand transport on a barchan dune. Geomorphology, 54(3-4). Pages 245-255. DOI: 10.1016/s0169-555x(02)00359-8

19. Jimenez, J.A., Maia, L.P., Serra, J., \& Morais, J. (1999). Aeolian dune migration along the Ceara coast, north-eastern Brazil. Sedimentology, 46(4). Pages 689-701. DOI: 10.1046/j.1365-3091.1999.00240.x

20. Maia, L.P. (1998). Procesos Costeros y Balance Sedimentario a lo Largo de Fortaleza (NE Brazil): Implicationes para una Gestion Adecuada de la Zona Litoral. $\mathrm{PhD}$ thesis, Faculty of Geology, University of Barcelona.

21. Markham, C.G., \& McLain, D.R. (1977). Sea surface temperature related to rain in Ceará, north-eastern Brazil. Nature 265(5592). Pages 320-323. DOI: 10.1038/265320a0

22. Nobre, P., \& Shukla, J. (1996). Variations of sea surface temperature, wind stress, and rainfall over the Tropical Atlantic and South America. Journal of Climate 9(10). Pages
2464-2479.
DOI:
$10.1175 / 1520-$

0442(1996)009<2464:vosstw>2.0.co;2

23. Philander, S.G.H., \& Pacanowski, R.C. (1986). A model of the seasonal cycle in the tropical Atlantic Ocean. Journal of Geophysical Research 91(C12). Pages 14192-14206. DOI: 10.1029/jc091ic12p14192

24. Noam, L., Tsoar, H., Herrmann, H.J., Maia, L.P., \& Claudino-Sales, V. (2009). Modelling the formation of residual dune ridges behind barchan dunes in North-east Brazil. Sedimentology 56(6). Pages 1623-1641. DOI: 10.1111/j.1365-3091.2009.01048.x

25. Levin, N., Tsoar, H., Maia, L. P., Sales, V. C., \& Herrmann, H. (2007). Dune whitening and inter-dune freshwater ponds in NE Brazil. Catena, 70(1). Pages 1-15. DOI: 10.1016/j.catena.2006.06.006

26. Sparavigna, A.C. (2015). Gimp Retinex for enhancing images from microscopes. International Journal of Sciences, 4(6). Pages 72-79. DOI: 10.18483/ijsci.758

27. Sparavigna, A.C.; Marazzato, R. (2015). Effects of GIMP Retinex Filtering Evaluated by the Image Entropy, arXiv preprint arXiv:1512.05653 

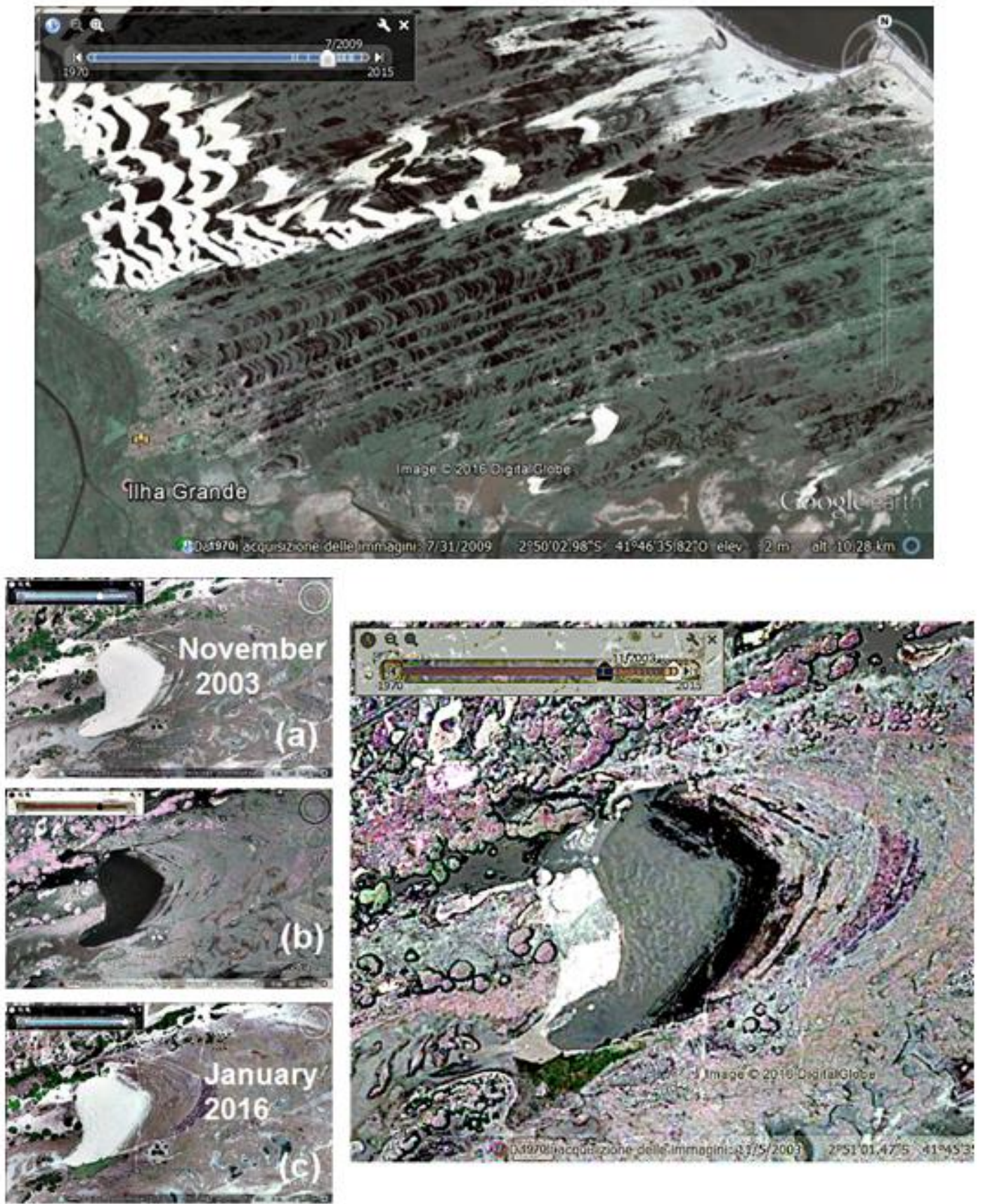

Figure 1: In the upper panel, we can see the dune field near the Ilha Grande municipality, located in the coastal region of Piauí, Brazil. In the lower part of this panel, we can see a solitary barchan. Let us consider two images of this dune from Google Earth time series. One is dated November 2003, shown in 1(a). The second is dated January 2016, 1(c). The image in the (b) panel is obtained from (a), with an inversion of colours. The images (b) and (c) are used has two semi-transparent layers to be merged with GIMP (the GNU Image Manipulation Program) to obtain the figure on the right, according to a method proposed and discussed in [14]. The black and the white areas show

the different positions of the dune. Using the ruler tool of Google Earth we can easily evaluate that the dune moved of about $110 \mathrm{~m}$, during the considered time interval. 

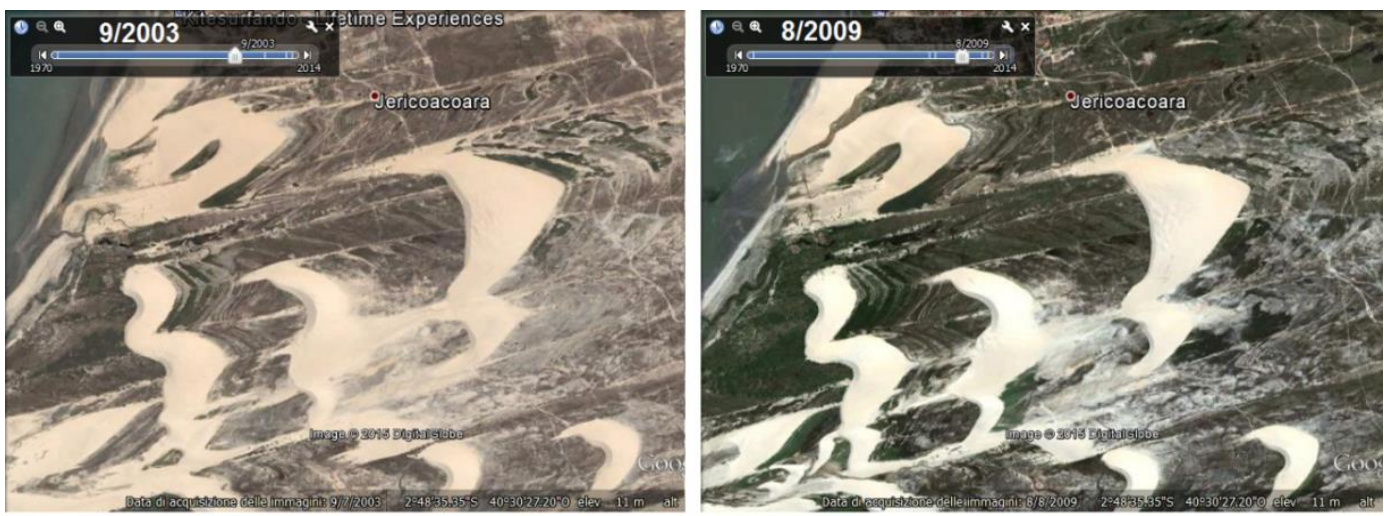

Figure 2: Some dunes in the coastal area of Jericoacoara in two images of a time-series of Google Earth.

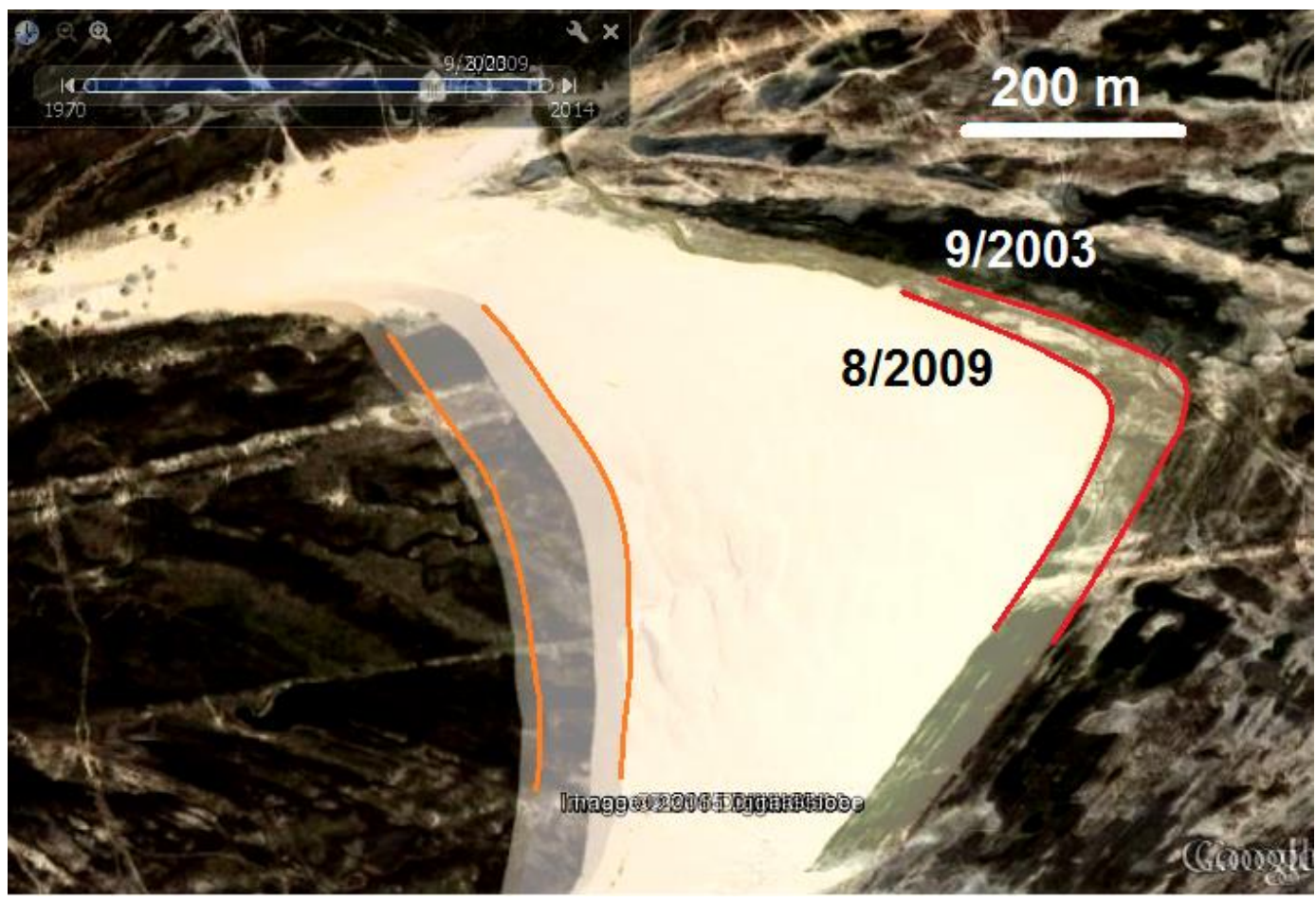

Figure 3: Let us choose the largest barchan in the two images of Figure 2, to measure its motion. With GIMP, we create an image from two layers, obtained from the images of Fig.2 [14]. Red lines mark the position of the toe of the dune, whereas yellow lines are giving the position of the brink. Using the pair of compasses of GIMP and the ruler tool of Google Earth, measurements are possible. The toe of the dune moved of about $70 \mathrm{~m}$, during a time interval of six years, from 9/2003 to 8/2009. It means a migration rate of about 11 meters per year. 

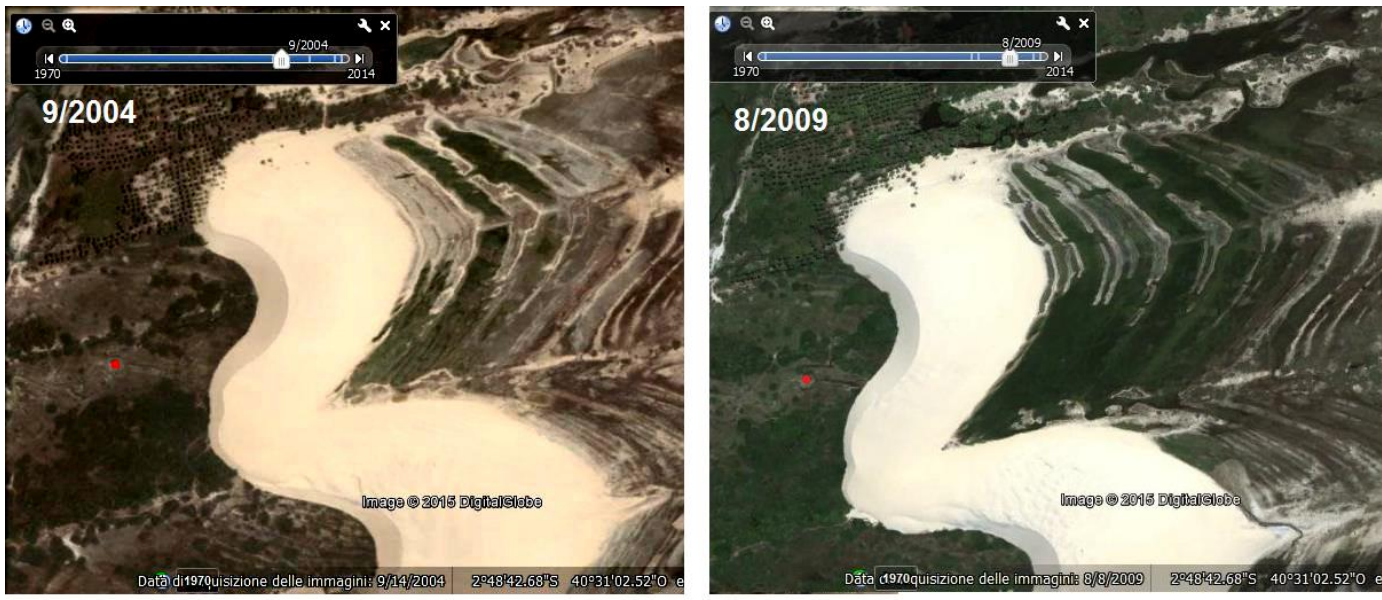

Figure 4: Other dunes of Jericoacoara from a time-series of Google Earth.
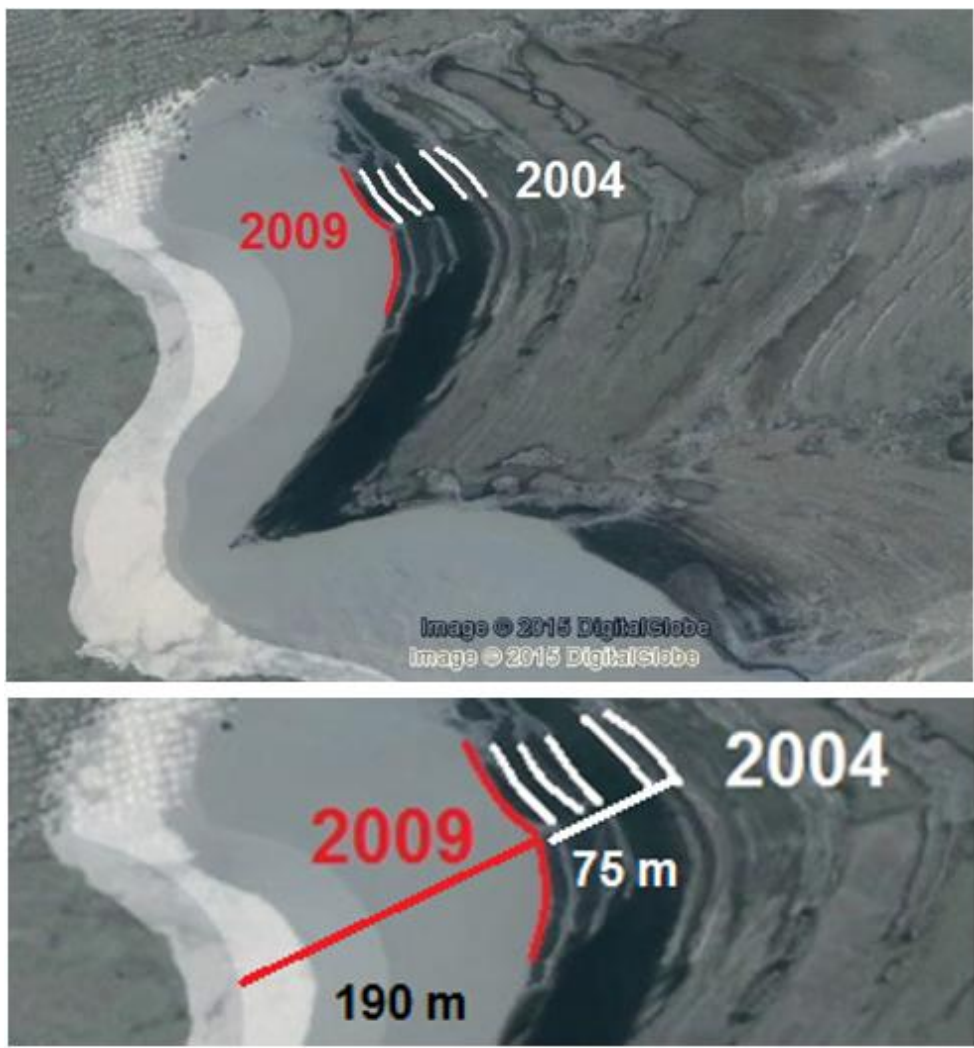

Figure 5: Again, we can compare the motion of a dune, using the two images of Figure 4 (this dune had been investigated also in Ref.24, where QuickBird images ranging from 9/2003 to 9/2004 were used). For this dune, we used GIMP to create an image from two layers adjusted with GIMP Retinex. Red line marks the position of the toe of the dune in 2009, whereas white lines mark its position in the previous years. Note the "footprints" of the dune. Using the ruler tool of Google Earth and the pair of compasses of GIMP, we can easily measure the distances as given in the lower part of the image. The dune moved of $75 \mathrm{~m}$ in five years, that is of 15 meters per year. Being this dune smaller, it moves faster than the dune given in the Figure 3. 

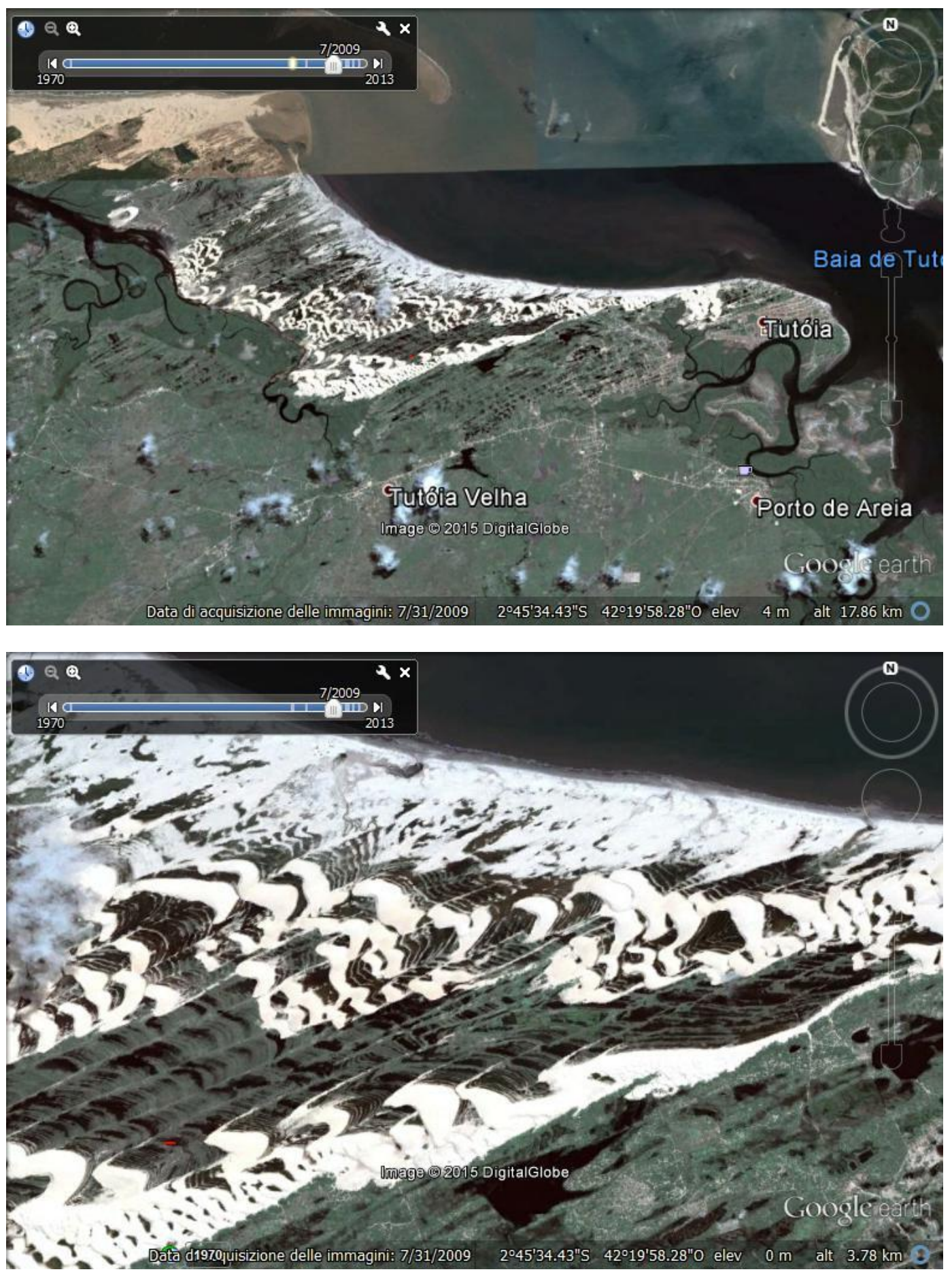

Figure 6: Dunes and their footprints of another coastal region of Brazil, near Tutoia. 


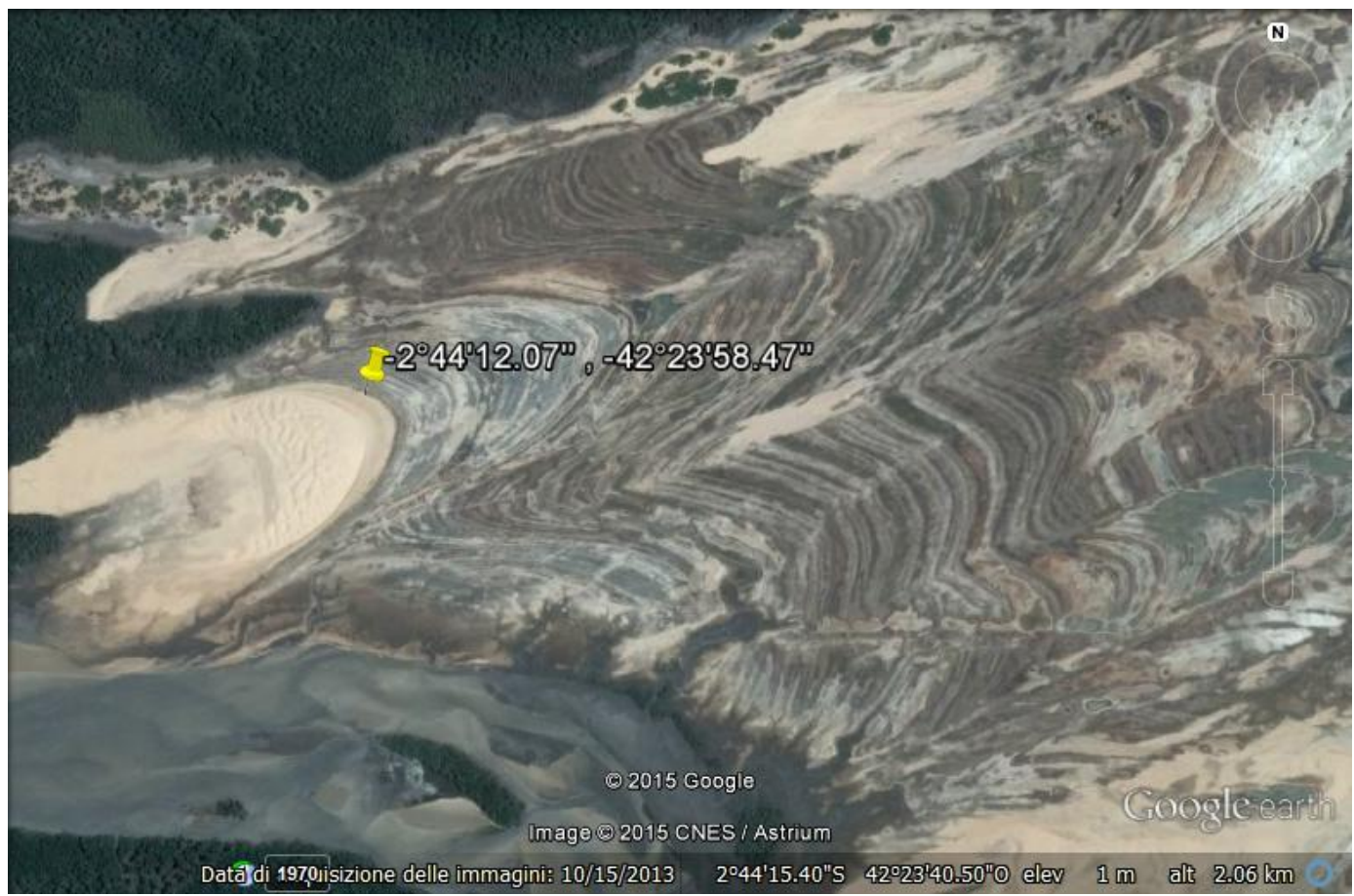

Figure 7: Footprints of dunes, near Tutoia. Some dunes had disappeared in the water.

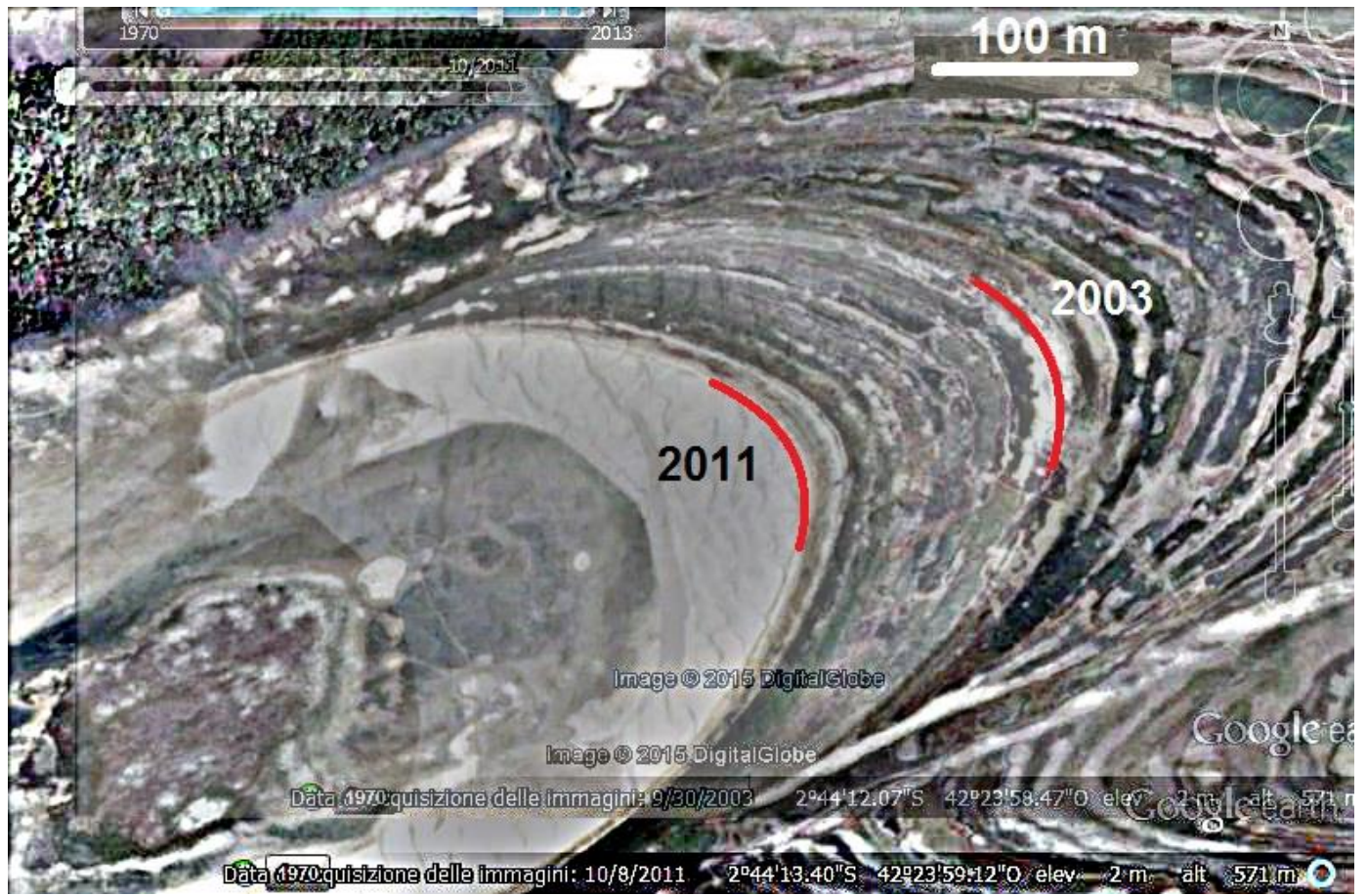

Figure 8: This image shows the series of footprints over 8 years for the dune in Figure 7. The red lines mark the position of the toe on 2003 and 2011. The toe of the dune moves of about 130 meters. 


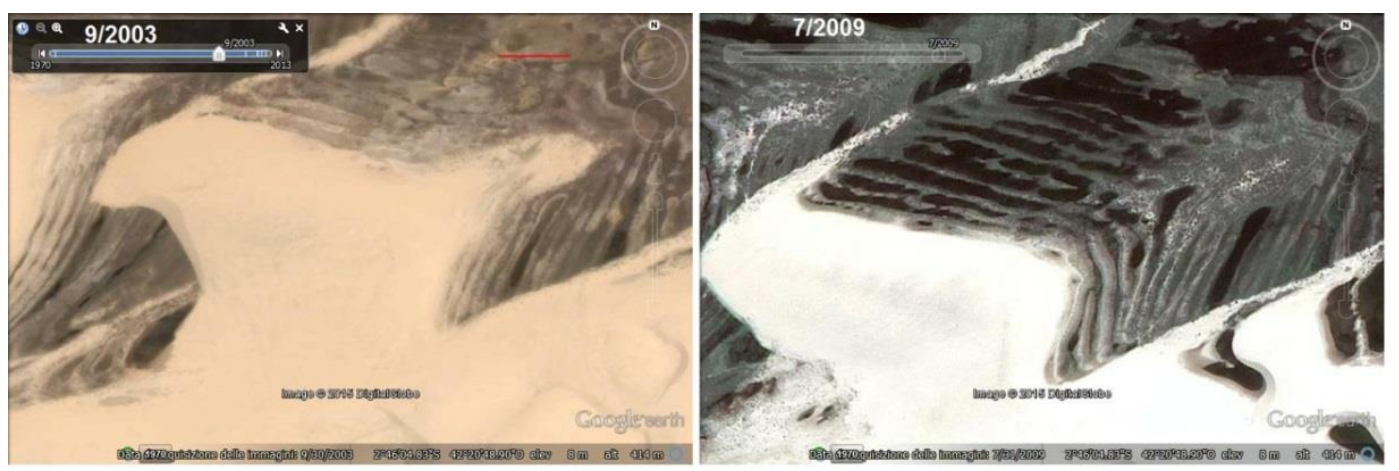

Figure 9: A dune and its footprints on the soil in a time-series of Google Earth.

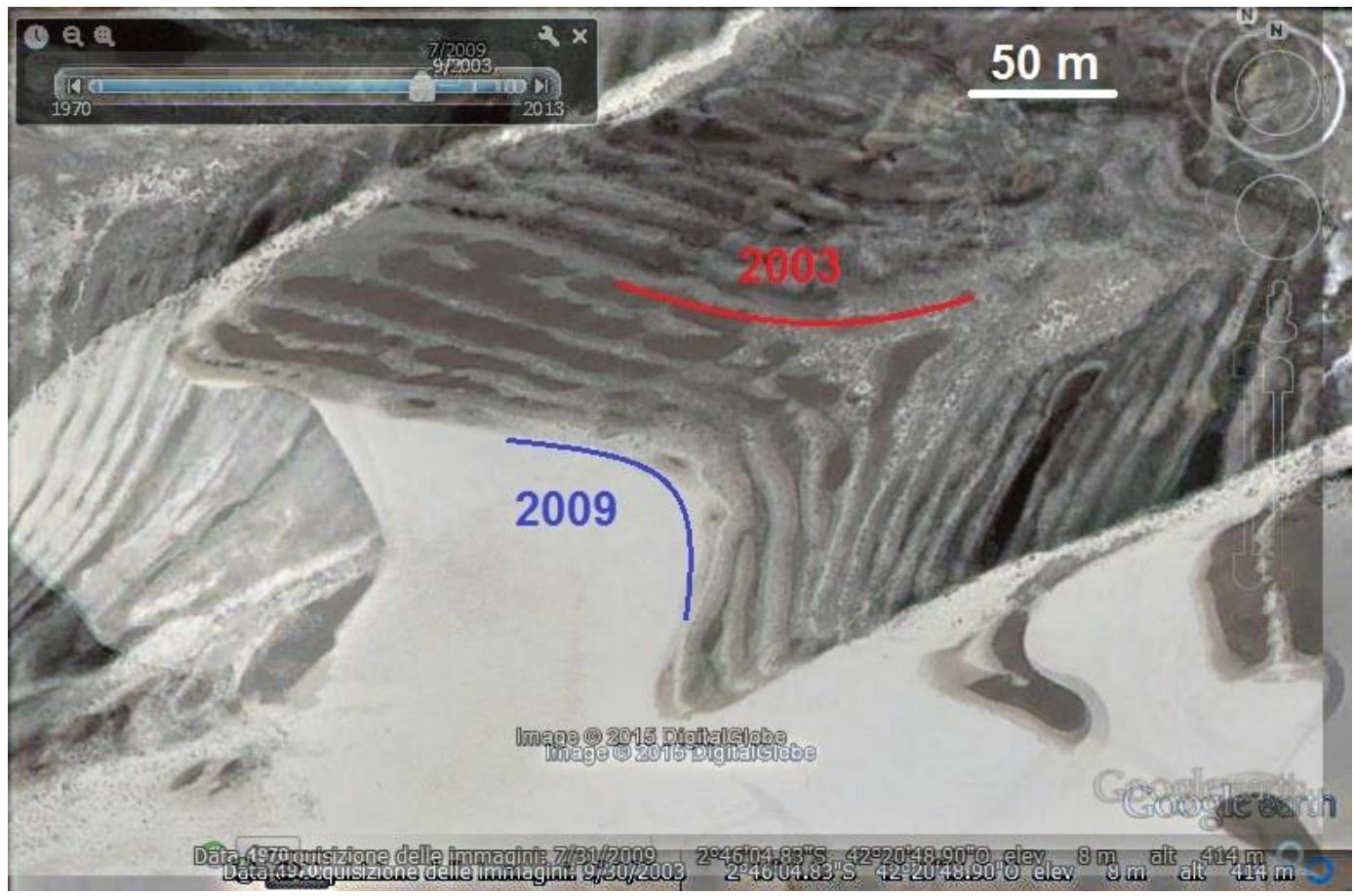

Figure 10: Also for this figure, we used GIMP to create an image from two layers adjusted with Retinex filtering. Red line marks the position of the toe of the dune in 2003, whereas blue line marks its position in 2009. The shortest distance between the red and the blue line is of $60 \mathrm{~m}$. 

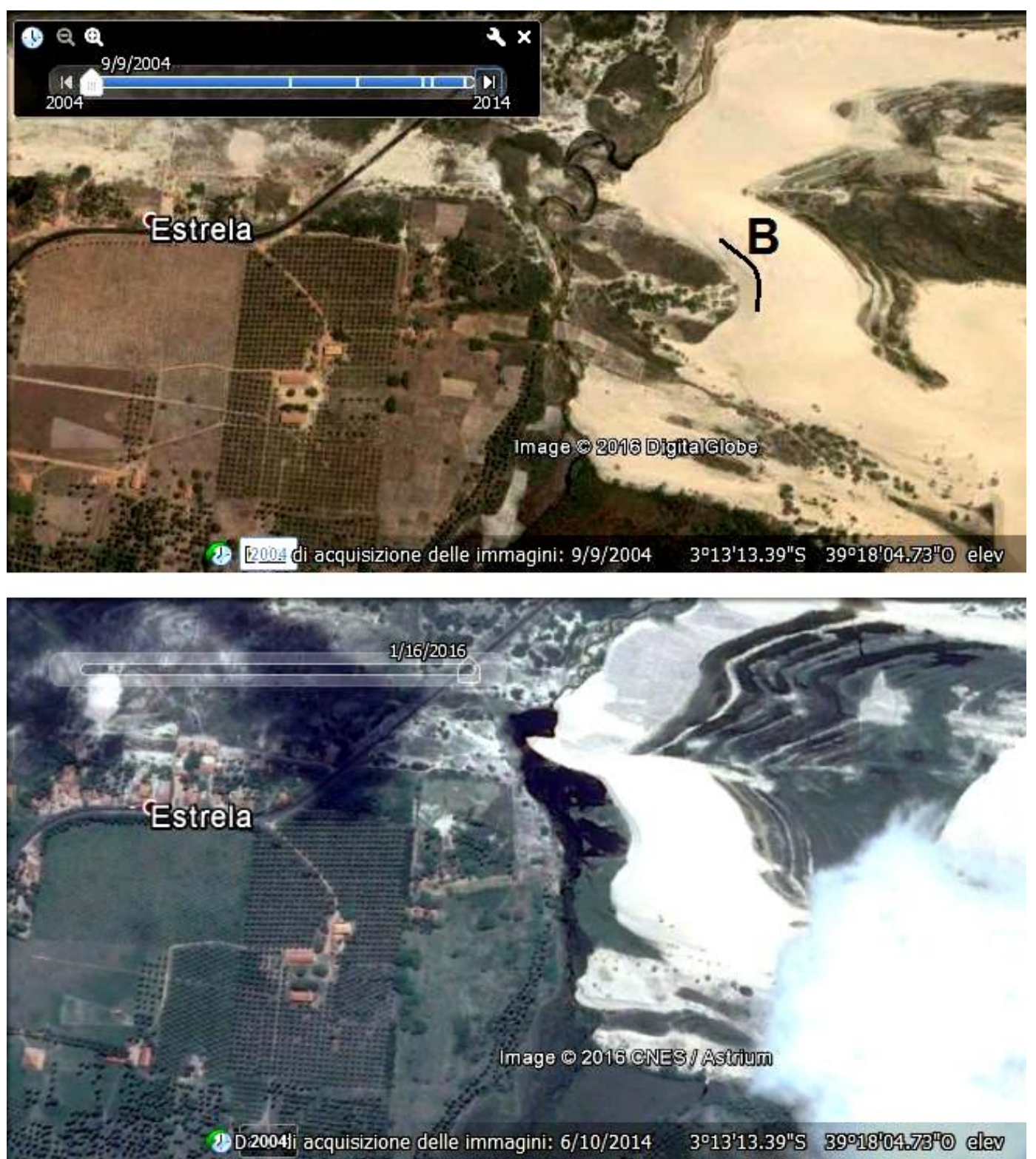

Figure 11: Google Earth is offering the possibility to investigate moving dunes and evaluate when they will become a problem for human activities. Here we can see Estrela (coordinates $3^{\circ} 13^{\prime} 8^{\prime \prime} \mathrm{S}, 39^{\circ} 18^{\prime} 23^{\prime \prime} \mathrm{W}$ ), on the north-eastern coast of Ceará, Brazil. The dunes move and change their form, as in the case shown by the two images dated September 2004 and January 2016. The brink B of the dune moves of about $150 \mathrm{~m}$. 